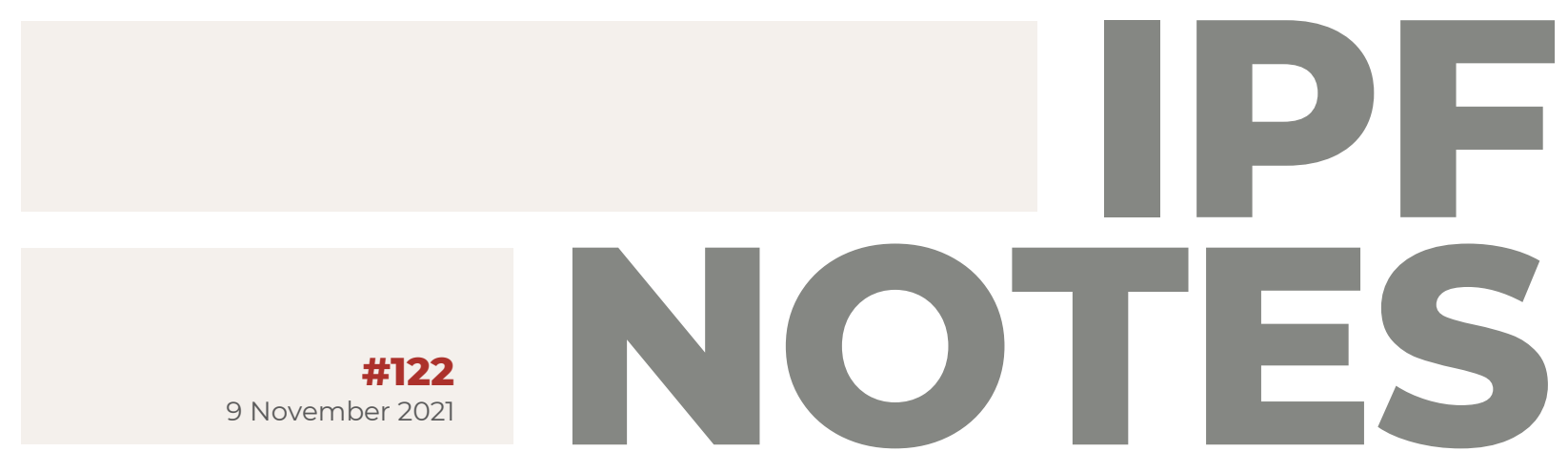

\title{
Overview of demographic measures at local and county levels in Croatia
}

\author{
Martina Pezer, Nora Mustać, Slavko Bezeredi \\ Institute of Public Finance, Zagreb
}

Local and regional self-government units, i.e., municipalities, cities and counties (hereinafter: local units), provide their residents with a wide variety of benefits with the aim of enhancing the demographical picture and social protection. The Central State Office for Demography and Youth (SDUDM) publishes an overview of all demographic measures and activities of local units in Croatia. The overview covers around 400 local units and is available in Excel format for 2020 (partially includes measures for the period 20182020) and 2027. Such an overview at local-unit level is a key starting point for public policy research and planning at all levels of government. The existing SDUDM database is highly useful and informative; however, all local units should be stimulated to introduce higher-quality reporting practices in the future in order 
to make the database more detailed, complete and accurate. Such a database would serve as a single source of information regarding benefits granted by local units and could also prove useful for potential beneficiaries to verify their benefit eligibility.

Measures of family and demographic policy are intended to help parents to deal with the challenges of parenthood, such as nurture and education costs and balancing professional and family life. Even though scientific literature shows no consensus on how and to what extent specific measures affect fertility rate growth, they are undoubtedly useful as they create a stimulating environment which reduces or removes obstacles to having the desired number of offspring in a family. Measures include various cash benefits, subsidies and in-kind benefits aimed at ensuring the well-being of families with children. Child benefit, tax allowance for dependent children and maternity and parental benefits are some of the better-known central government measures in Croatia. Apart from direct benefits intended for parents and their children, parents are often entitled to additional support through other general benefits, such as the guaranteed minimum allowance, health insurance subsidies and housing loans. Some of the most substantial benefits granted to parents by local units include kindergarten subsidies and grants for newborn children. Family and child benefits are the most common benefits provided at the local level, making up for $70 \%$ of

\footnotetext{
${ }^{1}$ This note is an outcome of the project "Impact of taxes and benefits on income distribution and economic efficiency" (IP-2019-04-9924) financed by the Croatian Science Foundation (HRZZ). The work of postdoctoral researcher Nora Mustać is also financed by HRZZ. Opinions, findings, conclusions and recommendations are the authors' own and do not necessarily reflect the views of HRZZ.
} 
social protection expenditures of local units in 2019 , whereas in the City of Zagreb they reach as high as $80 \% .^{2}$

Revoking existing family and demographic policy measures or adopting new ones requires detailed analyses; however, if we want the analyses to be comprehensive and precise, we require highquality databases. How does Croatia fare with regard to such databases?

At the central government level, the Croatian Pension Insurance Institute (HZMO) regularly publishes statistical information on the number of child benefit recipients. ${ }^{3}$ SDUDM publishes reports on demographic measures which include central government activities, children's budget, investments in pre-school education and demographic lexicon. ${ }^{4}$

The majority of local units publish an overview of measures provided to their residents on their respective websites. A consolidated overview of all local units, data and their measures is collected and published by SDUDM. SDUDM's overview of demographic measures presents basic information about local units in an Excel table alongside information about grants for

\footnotetext{
2 Authors' calculation on the basis of Croatian Bureau of Statistics data: Statistics in Line, Social protection (ESSPROS methodology) - by ESSPROS schemes (10.2.12. Social welfare in City of Zagreb and 10.2.16. Other social assistance at local level).

${ }^{3}$ Also see statistical data in machine readable form, available in open access.

4 The disbanded Ministry for Demography, Family, Youth and Social Policy used to publish statistical data on recipients of maternity and parental benefits, but this data is no longer publicly available.
} 
newborn children, various subsidies (school transport, school textbooks etc.), scholarships and related measures they provide. The 2021 overview presents the following set of information for each local unit:

- Development Index,

- number of households,

- number of families with children,

- grants for newborn children in 2020 and 2021,

- other benefits related to conception, pregnancy, infants and maternity,

- co-financing of healthcare costs,

- parents' kindergarten fees in 2021,

- co-financing of school children (textbooks, school meals, school transport, dormitory fees),

- co-financing of university students (scholarships and other stimuli for students),

- other education-related benefits,

- other housing measures etc.

The overview of measures, apart from raw data, also contains additional notes from local units that reveal their perspective with regard to demographic measures. An analysis of existing measures at the local level, based on SDUDM's data, reveals differences between local units. For this reason, an overview of all demographic measures published by SDUDM is a good starting point for public policy research and planning at all levels of government; at the 
same time, guidelines provided by international institutions should also be considered in this process. ${ }^{5}$

Croatia has occasionally seen catalogues of social benefits and aggregate lists of various measures; however, they are rarely available to the general public. ${ }^{6}$ SDUDM's overview of demographic measures is necessary not only for administrative reasons and conducting research but could be useful for (future) parents to collect valuable information. For instance, specific measures of local units are often hard to find or are not even listed at all on the units' websites. Local units who failed to deliver their data should be encouraged to do so as soon as possible. However, SDUDM's current overview of demographic measures, currently available in Excel format, should ideally be adapted to computerised data processing and harmonised so as to substantially facilitate analyses of data.

In addition, in their budget execution reports local units list the number of beneficiaries and overall costs of various benefits. This data should by all means be added to SDUDM's list of demographic measures. This would simplify the analysis process for executive authorities but would at the same time stimulate the scientific community to conduct specific analyses that could eventually help the authorities to adopt quality decisions. Transparency, integrity and accessibility of all information should be fostered at central

\footnotetext{
${ }^{5}$ According to World Bank recommendations, the target policies should be those aimed at balancing professional and personal lives.

${ }^{6}$ One example of a comprehensive catalogue of social benefits in Croatia was drafted through the project Synergistic social system in 2016, whereas the Institute of Public Finance published the Overview of social protection benefits in Croatia, covering the period 2011-2015.
} 
government level so that the public policy planning process in such an important area of interest for Croatia is of the highest quality.

In conclusion, the implementation of successful public policies at all government levels requires performance analyses of these policies, which cannot be done without quality data. Data is the foundation for introducing all changes and the main tool for monitoring whether the objectives of public policies have been met. All public policies, the current ones being no exception, should be monitored permanently and in an integral and transparent manner so that they could be adjusted to the beneficiaries' needs and the desired objectives. The Croatian Government showed initiative by announcing the launch of a web app that incorporates all social benefits in the social protection system at the national level and their eligibility criteria. This initiative is part of the National Recovery and Resilience Plan 2021-2026. The app would ideally be developed in the planned timeframe 2022-2024 and would serve as a single source of information for citizens to assure whether they qualify for specific benefits.

Even though they are, more often than not, limited in their fiscal capacity, local units could, indeed should, regularly monitor the needs of their residents since local budgets have a direct effect on the citizens' quality of life. For this reason, local policies need to be coordinated in a quality manner for the well-being of all citizens, children in particular. It should be noted that not all policies need to be aligned throughout the country as not all units share the same features, needs, problems and challenges; however, clear objectives and implementation plans should be defined at the country level, and all objectives planned in national strategies should be met. 